\title{
¿Hacia un pos-neoliberalismo?
}

\author{
Francisco Javier Ibisate
}

\begin{abstract}
Resumen
Este artículo contiene una serie de testimonios sobre la crisis del mercado financiero internacional. Uno de los testimonios más significativos fue el que se expresó en el foro de Davos, donde se dijo: "comprobamos algo ya presentido por muchos: nos hallamos de nuevo en el pos-neoliberalismo". Y continúa: "La globalización debe adquirir un compromiso social que no tenga como contrapartida la miseria y la exclusión de millones de seres en el planeta [...] Miseria y desempleo, destrucción masiva de la riqueza financiera y material . Estados sometidos a la especulación, un capitalismo salvaje que erosiona las normas más elementales de la convivencia, son algunos de los rasgos que advertirían una globalización irresponsable".
\end{abstract}

\section{Preludio: Davos, París y Seattle}

Parecería que por estar entrando en un nuevo milenio hay que buscar anuncios novedosos para vender nuevas ideas y que ésta fuera la razón del presente título: "un pos-neoliberalismo". La verdad es que lo que aquí se formula límidamente como una pregunta, en el foro de Davos se dijo sin ningún signo de interrogación: "comprobamos algo ya presentido por muchos: nos hallamos de nuevo en el pos-neoliberalismo". Los documentos de antecedentes de este foro económico ya presagiaban las tensiones que estallarían a lo largo del encuentro. "La globalización debe adquirir un compromiso social que no tenga como contrapartida la miseria y la exclusión de millones de seres en el pla- neta... Esta crisis (1997-1998...) es el resultado de una globalización que ha sido conducida de manera irresponsable. Los problemas creados por la mundialización han desembocado en una crisis 'sistémica'. O se diseñan nuevas medidas para hacer frente a la crisis o estamos condenados a entrar en un período de caos endémico y sistemática... Miseria y desempleo, destrucción masiva de la riqueza financiera y material. Estados sometidos a la especulación, un capitalismo salvaje que erosiona las normas más elementales de la convivencia, son algunos de los rasgos que advertirían una globalización irresponsable" (F. J. Ibisate, "En búsqueda de una tercera vía", ECA, 1999, pp. 465-467) Todo esto se dijo en el foro de Davos (1999). 
Desde mediados de 1999, en los intramuros de Europa occidental se habla y se discute sobre el documento inicialmente firmado por Tony Blair y Gerhard Schröder: "Europa: la tercera vía". No todos la traducen o la piensan aplicar en idéntica forma y han surgido algunas discrepancias entre los primeros ministros de Inglaterra, Alemania y Francia y otros gobiernos europeos. Valga recordar que el tílulo del documento es copia literal de una de las obras del gran economista checoeslovaco, Ota Sïk, La tercera vía (1972). Este inspirador de "la primavera de Praga" (1968) dice en su prólogo: "ni con unos ni con otros me puedo identificar en teoría. A ambos lados operan fuerzas conservadoras, cuya vinculación personal con uno u otro sistema les hace imposible reconocer los propios conflictos internos e impedimentos para el desarrollo" (ibidem). Esta es la inspiración que, dentro de menores divergencias, ha llevado a los gobiernos curopeos a reencarnar, en forma actualizada, el ideal de una "tercera vía" (R. Danhrendof, "La tercera vía", El País, 11 de julio de 1999; Pérez de pablos y C. Cifuentes, "El creador de la lercera vía defiende la renovación de los valores de la izquierda del centro", El País, 23 de julio de 1999; A. Ortega, "La tercera vía es la izquierda del centro", El País, 26 de julio de 1999; M. Noblecourt, "L'International Socialiste se livre a una célébration consensuelle de ses différences", Le Monde, 9 de noviembre de 1999). Estas reflexiones afloran en el congreso que comentamos a continuacón.

\subsection{El XXI Congreso de la Internacional So- cialista}

En la segunda semana del mes de noviembre 1999, el XXI Congreso de la Internacional Socialista, con la participación de 23 primeros ministros y 143 partidos miembros, firmó la "Declaración de París". Los portavoces de esta Internacional Socialista fueron los primeros ministros de Inglaterra, Tony Blair; de Francia, Lionel Jospin; de Alemania, Gerhard Schröder; del anterior gobierno español, Felipe González..., y participó el nuevo presidente de Argentina, Fernando de la Rua. La internacional socialista va abandonando progresivamente el eurocentrismo. Cincuenta nuevos partidos se han incorporado en los útimos siete años y doce nuevas organizaciones, entre ellas el Congreso Nacional Africano (CNA) de Nelson Mandela y Al Fatah de Yaser Arafat se sumaron durante la reunión de París, siendo 170 los miembros de la actual internacional.

Baste citar, de momento, algunos de los objetivos pactados en la "Declaración de París": (1) luchar contra la pobreza y el hambre, contra la explotación y la desigualdad de acceso a los recursos económicos y tecnológicos mundiales. Anulación de la deuda de los países más pobres; (2) luchar por los derechos humanos y la democracia; avanzar en el "derecho de injerencia por razones humanitarias": no amparar la impunidad de los dictadores; (3) construir la paz y la seguridad a través de un nuevo orden internacional; (4) reformar Naciones Unidas y ampliar el número de miembros del Consejo de Seguridad; reformar el Fondo Monetario Internacional, el Banco Mundial y la Organización Mundial del Comercio para adaptarlos a las nuevas realidades. Asegurar una mayor transparencia del sistema financiero internacional, a través de reglas. Luchar contra el crimen organizado, el tráfico internacional de drogas y el blanqueo de dinero. Crear un Consejo de Seguridad Económico en Naciones Unidas; (5) dar respuestas rápidas y sostenidas en el tiempo al problema de la protección del ecosistema; (6) Europa anticipa un modelo de regionalismo abierto y adecuado para hacer frente a los desafíos a los que no pueden responder eficazmente los estados-naciones. Fomentar este modelo en Asia, Africa y América Latina (J. L. Barbería, "La Internacional Socialista reclama la supremacía de la política sobre el mercado", $E l$ País, 9 de noviembre de 1999). Integramos más adelante estos temas junto con las agendas de Davos y Seattle.

\subsection{La conferencia de la Organización Mun- dial del Comercio: Seattle}

El 27 de noviembre de 1999, Luis de Sebastián anunciaba que "las organizaciones no gubernamentales para el desarrollo están afilando sus armas para lanzarse al asalto de la conferencia de la Organización Mundial del Comercio en Seattle, a finales de noviembre". Se habla de un "aislacionismo" de Estados Unidos, tema muchas veces repetido, dando a entender que sus políticos - como el senador Jesse Helms- quieren seguir interviniendo en el mundo unilateralmente, de acuerdo a su propia voluntad, sin las cortapisas de acuerdos pactados con otros países. Luis de Sebastián sostiene que al unilateralismo hay que oponer el 
multilateralismo; pero no "el multilateralismo hipócrita de las actuales organizaciones internacionales, cuyas estructuras reflejan el reparto del poder económico y militar en el mundo... Una de las lunciones de la Organización Mundial del Comercio tiene que ser precisamente la de parar a los unilateralistas americanos. Hay que ofrecerles la alternativa civilizada de poder discutir y someter a un arbitraje imparcial las disputas comerciales y no resolverlas como lo hicieron en otro liempo con la 'diplomacia de las cañoneras'..." No se trata de la desaparición, sino de la reforma radical y profunda de la Organización Mundial del Comercio ("Defensa del multilateralismo en el comercio internacional", El Pais, 27 de noviembre de 1999).

Si Luis de Sebastián anunciaba la "batalla de la Organización Mundial del Comercio", cuatro días más tarde, El País hablaba de los 20000 manifestantes que desbordaron la policía y retrasaron cinco horas la cumbre anuncia: "Bolas de goma, botes de humo y decenas de detenciones convierten Seattle en una batalla campal". Con la misma fecha, el I de diciembre, Le Monde elevó a 40000 el número de manifestantes. "Abajo Babilonia" decía una pancarta. Para los manifestantes "la Organización Mundial del Comercio es la Babilonia del segundo milenio, una especie de siniestra organización de rostro anónimo, convertida en el motor de una globalización que sólo favorece a las grandes empresas multinacionales". Los delegados de los 135 países miembros no pudieron acudir a la ceremonia de inauguración, que se inició como un fiasco espectacular. La multitud de obreros, estudiantes y militantes venidos de otros países se manifestaron en contra de una mundialización que ignora sus consecuencias sociales. Los manifestantes dijeron estar en la calle "para dar la palabra a aquellos que jamás la han tenido y para que la Organización Mundial del Comercio escuche la voz de los ciudadanos...". "La ley de las multinacionales no es la democracia". Se trata de que los pequeños países se hagan escuchar. La Organización Mundial del Comercio ha cristalizado múltiples protestas de amplios grupos contestatarios. "Gracias a la Organización Mundial del Comercio por habernos puesto en movimiento", decían los manifestantes (J. Valenzuela, "20.000 manifestantes desbordan la policía y retrasan 5 horas la cumbre de la OMC", El País, 1 de diciembre de 1999; L. Caramel, "Des citoyens, pas de consomateurs: 40000 manifestants a Seattle", Le Monde, 1 de diciembre de 1999).

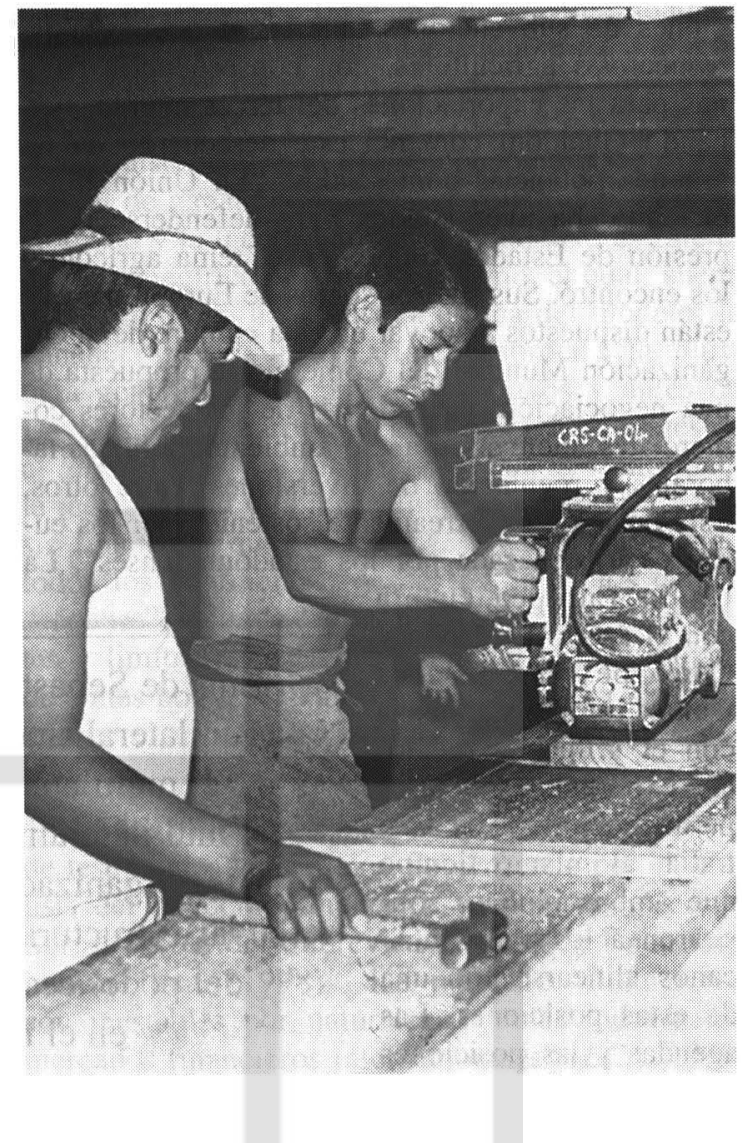

Conviene recordar que Seattle es la cuna de algunas multinacionales, como Boeing, Microsoft, Amazon, Starbucks... Ello explica que medio centenar de grandes empresas norteamericanas tuvieran ese mismo día en Seattle una reunión de incógnito, para defender las ideas de libre comercio que promueve la Organización Mundial del Comercio, y expresar su oposición a las protestas de ecologistas y sindicales. Por encima de estas manifestaciones a favor de los países que no tienen voz en la economía internacional, desde el primer día de esta "ronda del milenio" aparecen fuertes tensiones sobre el orden de la agenda, dando a entender que el centro de atención sería la batalla entre la Unión Europea y Japón contra Estados Unidos.

De poco sirvió limar posiciones en una reunión vespertina, a la cual acudieron los secretarios de comercio internacional de Estados Unidos y Europa. Cada grupo trató de buscar sus aliados en el complejo tema de la competencia desleal (dumping y antidumping), amén de las mutuas acusa- 
ciones de subvenciones abiertas u ocultas a las respectivas agriculturas, con consecuencias dañinas para las exportaciones del tercer mundo. Fernando Gualdoni comenta este desacuerdo de las grandes potencias comerciales: "La Unión Europea buscaba ayer aliados para defenderse de la presión de Estados Unidos en el tema agrícola y los encontró. Sus futuros socios de Europa del este están dispuestos a apoyar en esta cumbre de la Organización Mundial del Comercio la propuesta de una negociación que, además de los sectores comerciales, incluya el medio ambiente, políticas laborales y regulación de inversiones, entre otros. Esta posición es férreamente sostenida por los europeos y rechazada por los estadounidenses". La Unión Europea cuenta con el apoyo de Japón y Corea del Sur. Estados Unidos reforzó su alianza con el grupo de dieciocho exportadores de otros países, sobre todo de Australia, al mismo tiempo que ambos bloques solicitaron a los países africanos alinearse con una de estas posiciones. Las agendas y las posiciones son confrontativas desde el mismo inicio, y aunque se quiera presentar al comercio abierto como motor del desarrollo, se reconocen el agravamiento de las desigualdades en la distribución del ingreso y los problema planteados por el medio ambiente, las normas laborales y la falta de transparencia $(F$. Gualdini, "Europa consigue el apoyo de los países del este en su batalla contra Estados Unidos", El País, 1 de diciembre de 1999).

William Pfaff, experto estadounidense en política comercial, plantea su tesis en un artículo aparecido el 1 de diciembre: "El comercio es inseparable de la política". El comercio no es una mera cuestión económica, como se piensa en los países industrializados y debe abordarse en el contexto político y social. Sindicatos y ecologistas piden que se preste atención a los daños causados por la expansión del comercio a las normas laborales, a la calidad de la vida, a la ecología y a la estabilidad social y política. Distinta ha sido la postura de los gobiemos, los organismos y las empresas transnacionales, que buscan la liberalizción de comercio como un puente hacia el crecimiento económico, y se oponen a que factores ajenos a los puramente económicos afecten los intercambios del mercado. Sin embargo, ninguna economía real está exenta de distorsiones impuestas por la política, la sociedad y la vida en sí. Aunque se acusan mutuamente, tanto Europa como Estados Unidos subvencionan sus exportaciones agrícolas y el Atlántico es testigo de las crónicas disputas sobre productos genéticamente modificados. Al haberse desarrollado en ambos continentes una agricultura industrial, surge la lucha por invadir mercados externos, a modo de guerras agrícolas. Con ello, sufre la agricultura artesanal y orgánica de esos países y sufre mucho más la agricultura de subsistencia de los países en desarrollo (W. Pfaff, "El comercio es inseparable de la política", El País, 1 de diciembre de 1999).

Por añadidura, la mundialización y la liberación se refieren más a las transacciones financieras que al comercio de mercancías. Los derivados financieros superaron, en 1997, doce veces el valor de toda la economía mundial. William Pfaff cierra su artículo con un párrafo que recuerda las lamentaciones de Davos: "Todo esto es eminentemente político. Durante los últimos años, la liberación de los intercambios financieros y los flujos especulativos de inversiones, junto con las prácticas abusivas de sociedades anónimas no controladas, han hecho que las economías prosperasen y se hundiesen, han arruinado divisas, puesto de rodillas a las economías asiáticas, atacado la agricultura tradicional y las industrias artesanales, desestabilizando gobiernos y provocando violencia y convulsiones sociales, al mismo tiempo que beneficiaban a las economías desarrolladas y a ciertos sectores de los países en vías de desarrollo" (ibidem).

Estas breves anécdotas y testimonios nos sitúan en la apertura de la reunión de la Organización Mundial del Comercio, en Seattle, cuyos principales debates comentamos más adelante, apuntando desde ahora que no se logró un acuerdo final. No hubo acto inaugural y no hubo acuerdo final. Este breve preludio nos permite reflexionar sobre el realismo y la realidad de la crisis sistémi- 
ca del neoliberalismo. En los años setenta entró en crisis el llamado Estado social de bienestar, lastrado por el excesivo gravamen del gasto público, de la seguridad social, incluidos los costos armamentísticos (ECA, 1996, pp. 865-877). En Europa occidental, mutatis mutandis, los gobiernos laboristas y socialdemócratas estarían gestando una reencarnación actualizada de sus valores sociales. En la década de los ochenta (1989-1991), los así llamados "socialismos reales" se desintegraron política y económicamente, dando pie a la teoría del fin de la historia. Al clausurar la década de los noventa y cerrando el presente siglo, sobran las razones teóricas e históricas para cuestionarse si el neoliberalismo enfrenta una crisis sistémica.

\section{2. ¿Crisis sistémica del neoliberalismo?}

Comenzamos haciendo una pregunta y no una afirmación, aunque habría razones suficientes para ello. En artículos anteriores planteábamos la pregunta y la respuesta en otros términos. "Quienes hemos recorrido unas cuantas décadas entre capitalismo y socialismos reales nos permitimos, al finalizar el siglo, plantear un interrogante: por qué estos dos sistemas, opuestos en tantos aspectos, coinciden históricamente en un rasgo común, el rechazo a la autocrítica". Por ello, en dos artículos complementarios recogimos un conjunto de testimonios críticos de autores autorizados, quienes se expresan desde ambas riveras del Atlántico ("Sugerencias al neoliberalismo: haga su autocrítica", Realidad, 1998, pp. 9-32; "Neoliberalismo y globalización”, ECA, 1998, pp. 20-21).

Aparte de que el título se plantea como pregunta, también el término "crisis sistémica" lo traducimos en su sentido etimológico: juzguemos, evaluemos y valoremos sus objetivos teóricos frente a sus resultados reales. En otras palabras, es necesario que los "sistemas económicos se comparen y se enfrenten con sí mismos", en un proceso de autocrítica. Dado que los grandes gestores del neoliberalismo se resisten a hacer su autocrítica, no nos queda otra vía abierta que una selección representativa de críticas autorizadas, referidas a algunas graves perturbaciones financieras, económicas y humano sociales con que cerramos el siglo.

\subsection{La volatilidad de los capitales financieros}

En el foro de Davos se llegó a expresar una conclusión sorpresiva: "Así, en último término, parece que hay que instalarse en la volatilidad financiera y en la inestabilidad económica y aprender a vivir en un mundo incierto, pero creativo y con potencial de ganancia" (ECA, 1999, p. 466). ¿Qué quiso decir este ilustre ponente? ¿Que el potencial de ganancia justifica la volatilidad, la inestabilidad y la incertidumbre mundial? No es éste el mejor panegírico del neoliberalismo, el cual suena más bien como una caústica crítica del modelo: la ganancia privada justificaría el desorden y la injusticia general. Por supuesto, en Davos y antes de Davos se escucharon muchos testimonios opuestos al laissez faire y al laissez passer de la volatilidad, la inestabilidad y la incertidumbre mundial. La crisis financiera que, desde 1997, viene sacudiendo todos los continentes, desde los "modelos de los dragones", incluido Japón, hasta los países emergentes y limítrofes, así como también las "burbujas" de tantas bolsas de valores, es una prueba histórica de que el modelo ha entrado en una "crisis sistémica".

En los arlículos citados se integran un conjunto de testimonios autorizados, comenzando por el análisis del conocido financiero y filántropo George Soros, acerca del imprevisible mercado financiero internacional (1998): "los mercados financieros son inestables por naturaleza, y más todavía los mercados financieros internacionales" (ECA, 1999. p. 899). Baste recordar unos breves testimonios. La primera cita es de Kissinger: "lo que en un primer momento se interpretó como un desequilibrio temporal se está convirtiendo en una crisis del sistema financiero mundial. Las instituciones que tratan con las crisis financieras internacionales necesitan una reforma". El profesor de Harvard Dani Rodrik, al exponer lo que parece ser el pensamiento ahora predominante del Banco Mundial, señaló que "hay pocas evidencias sobre los beneficios de la libre movilidad de capitales y demasiados signos de los costos que la política de apertura conlleva". Joseph Stiglitz, vicepresidente del Banco Mundial, afirma que puede ser una idea peligrosa que los países abran sus economías a un libre flujo de capitales, aunque eso es lo que están pidiendo los países industrializados. Según Stiglitz, "los estudios no han demostrado una correlación entre la liberación de capitales y el crecimiento económico. Dicha liberación suele ir asociada con crisis financieras y aumentos de la desigualdad de los ingresos".

Samuelson y Krugman plantean límites a la acción de estos mercados: "la política económica se 
ha vuelto prisionera de los inversores frívolos. ¿Puede cambiar? Sí, pero la solución está estigmalizada, démodé y nadie osa sugerirla: esta política cs el control de cambios". J. Bhagwati, defensor del libre comercio de bienes, afirma que "los argumentos de los enormes beneficios de la movilidad del libre capital no son persuasivos". Alan Grenspan, director de la Reserva Federal de Estados Unidos, reconoce que es difícil controlar esos miles de millones de dólares que se mueven al apretar un botón de una computadora: "dadas las extraordinarias facilidades de comunicación, disponibles virtualmente alrededor de todo el globo, el comercio puede ser iniciado casi desde cualquier lugar; cualquier regulación directa de Estados Unidos restringiendo su flexibilidad, sin duda alguna induciría a que los fondos más agresivos emigrasen de nuestra jurisdicción". Conclusión contradictoria: una jurisdicción sin jurisdicción. Michael Elliot comenta: "a la pregunta ¿quién está a cargo de la economía global? podemos ahora responder: nadie. Un mundo sin controles, sin reglas, es un mundo sin seguridad". Estos son algunos de los testimonios citados al describir la crisis financiera, iniciada en el continente sudasiático y que, a modo de efecto dominó, ha sacudido tantas economías nacionales. Se ha hablado de "economía de casino", pero incluso los casinos tienen sus reglas.

Uno de los principales objetivos que se propone la Internacional Socialista en su "Declaración de París" es la reforma de los organismos internacionales (Fondo Monetario Internacional, Banco Mundial y Organización Mundial del Comercio): "acabar con los flujos incontrolados de capitales, culpables, en opinión de los socialistas, de las conlinuas crisis financieras y colocarlos bajo el foco liscalizador, constituye su respuesta a un fenómeno que amenaza con contaminar el sistema democrálico. Sin transparencia y sin control, perdurando paraísos fiscales, será cada día más difícil luchar contra el blanqueo de capitales procedentes de prácticas corruptas enraizadas en algunos países y de flujos contaminados con origen en la criminalidad organizada internacionalmente".

De acuerdo a fragmentos disponibles, la "Declaración de París" afirma que la deriva de los capitales constituye una amenaza en toda regla a la seguridad de las naciones: "el campo de la paz internacional, de la seguridad, tiene hoy una diinensión económica y financiera, que tenemos que enfrentar con valentía desde posiciones progresis- tas. Por eso es urgente asegurar una mayor transparencia del sistema financiero internacional, imponer reglas de prudencia a todas las instituciones financieras, incluso a los fondos de inversión especulativos y a las entidades extraterritoriales; abolir los paraísos fiscales; involucrar a las entidades prestamistas en la resolución de las crisis que contribuyen a provocar". La Internacional Socialista solicitó la creación de un Consejo de Seguridad Económica bajo los auspicios de Naciones Unidas. "Frente al capital triunfante y el predominio de las leyes del mercado, los partidos socialistas reclaman la primacía y la autonomía de la política como único instrumento que puede permitir defender los intereses generales". Se sugiere aplicar la tasa Tobin a las transacciones monetarias, medida que encuentra grandes resistencias en los medios financieros, sobre todo norteamericanos (H. M. Wachtel, "Trois taxes globales pour maitriser la speculatión", Le Monde Diplomatique. octubre de 1998, pp. 20-21; N. Chomsky, "Finance et silence", ibídem, diciembre de 1998, p. 21).

\subsection{La Organización Mundial del Comercio de Seattle: fracaso y victoria}

Del mercado financiero mundial pasamos al mercado internacional de bienes y servicios. Esta reunión de la Organización Mundial del Comercio, que se inició sin acto inaugural, se cierra sin un acuerdo final, transfiriendo a la sede de Ginebra las deliberaciones sobre los puntos pendientes. El desacuerdo concierne incluso a los mismos puntos pendientes. La reunión resultó ser bastante caótica, tanto por los enfrentamientos previsibles entre los representantes de los 135 países miembros, como por las protestas y manifestaciones de las organizaciones no gubernamentales, los ecologistas, los sindicatos, los estudiantes..., en representación de la sociedad civil y en la defensa de los $\sin$ voz en estos organismos internacionales.

La Organización Mundial del Comercio de Seattle se asemeja a un tablero de ajedrez, con más de dos contendientes, donde cada uno estaría dispuesto a perder algun peón siempre que el oponente quede en posición difícil de jaque mate. Clinton y sus aliadas norteamericanas, las megaempresas, esperaban una victoria rápida, de sesgos humanitarios, algo así como la "guerra humanitaria" de Serbia y Kosovo. Ahí surgió el fracaso.

En la normativa de la Organización Mundial del Comercio, el acuerdo final requiere el voto 
unánime de los 135 representantes de los países miembros. En Seattle triunfó el desacuerdo de los países emergentes y en desarrollo, los cuales se negaron a firmar los acuerdos finales, porque ni siquiera habían sido consultados. Sus observaciones a los borradores previos no fueron tomadas en cuenta. La voz de los sin voz fue su desacuerdo, que ha sido interpretado como su victoria. Los periodistas de El Pais y Le Monde coinciden en los mismos argumentos. Los países en desarrollo no han tenido que firmar un documento, no deseado, puesto que no habían sido consultados. Los países africanos denunciaron acremente su marginación en todo el proceso de negociación. No hay transparencia alguna en todo este proceso y "americanos y europeos juegan con nosotros con la política del palo y la zanahoria". Cuando las discusiones, a puerta cerrada, se elernizaban sin que se filtrase la menor información, los delegados de los países pobres, sin ánimo e ilusión, aguardaban pacientemente en los pasillos. "No sabemos qué decisiones se van a tomar y una vez más se nos pedirá subscribir un texto que ni tendremos tiempo de leer". "La Organización Mundial del Comercio ha sido, por fin, obligada a entrar en razón. No se puede proseguir la liberalización sin tomar en cuenta las preocupaciones de los ciudadanos" (L. Caramen, "Une victorie pour les pays pauvres et pour les mouvements de citoyens", Le Monde, 4 de diciembre de 1999).

\subsection{El carrefour de los enfrentamientos}

Si en las calles de Seattle hubo toque de queda y fuego cruzado, en las sesiones se mantuvieron dos líneas de enfrentamiento: la doble diferencia entre norteamericanos y europeos, y entre países ricos y pobres. Simplificando el complejo embrollo de las agendas y subagendas, un primer debate entre Estados Unidos y Europa se centró en el tema de las subvenciones y protecciones para la agricultura. El borrador de un pacto incluía los siguientes temas: "sustanciales reducciones de las subvenciones agrícolas europeas, la creación de un grupo de trabajo sobre biotecnología, la ampliación hasta el 2001 de la moratoria sobre tasas de comercio en Internet, incremento de los inter- cambios en finanzas y telecomunicaciones y reforma de las leyes norteamericanas contra el dumping o competencia desleal".

Al querer concretar los términos del borrador, surgieron las discrepancias. Para la Unión Europea, la "agricultura" no es una simple rama económica cualquiera, sino que goza de una "multifuncionalidad" con profundas implicaciones sociales, culturales y medio ambientales. Aunque Estados Unidos y el grupo de Cairns (dieciocho países agroexportadores) aceptan estas preocupaciones no comerciales, solicitaron eliminar del texto el término "multifuncional" y la suspensión de todos los subsidios a los productos agrícolas. El representante europeo, P. Lamy, estuvo a punto de ceder ante las exigencias de Estados Unidos, pero fue obligado a dar marcha atrás por no haber consultado a la totalidad de lo quince ministros europeos, que se negaban "a tragar alimentos genéticamente modificados". Las mismas organizaciones no gubernamentales advirtieron que "si Estados Unidos, el mayor exportador de productos genéticamente modificados, se sale con la suya y cuela este tema en el marco de la Organización Mundial del Comercio, aumentará la presión para que los países pobres abran sus mercados a los alimentos biotecnológicos". La representación estadounidense explicó que "los cultivos genéticamente tratados pueden eliminar el hambre de miles de millones de personas y que no se ha probado científicamente que estos alimentos son nocivos para la salud". Precisamente, "esta duda científica es la razón mayor para que Europa se oponga a la importación de algunos de estos alimentos" (J. Valenzuela y F. Gualdoni, "Clinton llama a los líderes mundiales para lograr una nueva ronda para liberalizar el comercio", El País, 4 de diciembre de 1999; F. Gualdoni, "La Comisión Europea cede a las presiones de Estados Unidos para negociar sobre transgénicos", El País, 3 de diciembre de 1999).

Dejando en vía muerta el problema de los productos transgénicos, afloró el debate de las multi- 
formes ayudas a los agricultores europeos y norteamericanos. En Europa, la "política agrícola común" es considerable: 40.5 mil de millones de euros. Estos apoyos son multiformes: el más importante es la ayuda directa para compensar o mantener precios garantizados. Algunos productos mediterráneos reciben ayudas de acuerdo al volumen de producción. Existen precios garantizados para cereales y lácteos, así como derechos de aduana que aseguran la producción comunitaria. Aunque en menor proporción, también se conceden ayudas, llamadas "restituciones", para fomentar la exportación. Similares son las ayudas a los agricultores norteamericanos, aunque en forma menos visible. Estas ayudas alcanzan los $22 \mathrm{mil}$ de millones de dólares para el año 2000 , bajo el concepto de "precios mínimos garantizados"; también en Estados Unidos existen las restituciones. Se añaden los créditos a la exportación que, de acuerdo a Bruselas, no son conformes con las normas de la Organización Mundial del Comercio (B. Stern, "Des aides multiformes aux agriculteurs européens et américains", Le Monde, 5 de diciembre de 1999).

Este descubrimiento de una conocida realidad motivó la protesta de los países pobres - apoyados por ecologistas, sindicatos, organizaciones no gubernamentales y estudiantes - contra Europa y Estados Unidos. Los países en desarrollo argumentan que la "multifuncionalidad" de la agricultura europea "es simplemente una treta de la Unión Europea y Japón para evitar la presión que los forzará a desmantelar su sistema de subvenciones agrícolas". Los países pobres esperan una severa reducción o la eliminación de los aranceles a la importación de productos provenientes de países menos desarrollados. Incluso esta pequeña esperanza ha generado desconfianza y crispación ( $F$. Gualdoni, "Los países pobres exigen a Europa que desmantele las ayudas a la agricultura", El País, 2 de diciembre de 1999).

La "revuelta de los marginados" enfiló también a Estados Unidos. Bill Clinton, en su alocución sobre la liberalización del comercio internacional, solicitó "derechos laborales mínimos para todo el tercer mundo: no se trata sólo de bajar las barreras comerciales, sino de subir los niveles de vida". Se refería en concreto a las formas aberrantes del trabajo infantil. Esta intervención "humanista" de Clinton dio cauce a la ironía de los representantes europeos; se trataba de una evidente contradicción entre un Clinton, convertido en defensor de los trabajadores y un Estados Unidos que no ha ratificado muchos de los tratados laborales de la Organización Internacional del Trabajo (OIT). En los países en desarrollo, la sugerencia de Clinton generó temor, porque los países ricos podrían aplicar sanciones y dificultar las exportaciones a los que no aplicar normas laborales. China advirtió que "los derechos laborales no es un asunto que se puede debatir en la Organización Mundial del Comercio". Esta sugerencia del Clinton, "de reforzar las medidas de castigo contra aquellos países que incumplan los estándares mínimos laborales, fue la gota de agua que hizo rebosar el baso de la paciencia de los países pobres, principalmente los africanos, que ya se sentían ignorados por Estados Unidos y la Unión Europea en todos los temas que se negocian en Seattle". Repiten el mismo argumento: Estados Unidos ha ignorado durante muchos años los tratados internacionales de la Organización Internacional de Trabajo y ahora pretende impulsar sanciones contra los que incumplan tales tratados, "haciéndolo además como anfitrión de una cumbre sobre el comercio internacional" (J. Valenzuela, "Clinton pide derechos laborales mínimos para todo el tercer mundo", El País, 3 de diciembre de 1999; F. Gualdoni, "Los países en desarrollo intentan separar comercio y derechos laborales", El País, 4 de diciembre de 1999).

\subsection{La voz de los sindicatos}

Las organizaciones no gubernamentales, los sindicatos, los ecologistas... se manifestaron en Seattle como la voz de la sociedad civil. Esta conferencia de la Organización Mundial del Comercio hay que leerla desde el proceso de la mundialización. Una mundialización que no lo es tanto, porque buena parte de los tres continentes no interesan al gran capital. "Más del 70 por ciento de las grandes multinacionales son estadounidenses, mientras que apenas un 5 por ciento pertenece a algún país en vías de desarrollo". La mundialización no está resolviendo los problemas del desempleo y de la desigualdad social. "Las organizaciones sindicales debemos dejar claro que, bajo las diferentes posiciones ante la reunión de la Organización Mundial del Comercio, subyacen diversos planteamientos políticos: aquellos que consideran que el dios mercado y su hija predilecta, la competitividad, todo lo pueden y todo lo dirigen; 
y otros que afirmamos con absoluta convicción que sólo con medidas correctoras ejercidas desde la razón social, desde lo público, desde lo civil, es permisible el capitalismo de este fin de milenio".

Para el movimiento sindical, la mundialización debe basarse en la justicia social, la democracia y la igualdad. Estas consignas implican ciertas exigencias a países desarrollados y en vías de desarrollo. "El movimiento sindical exige de la Organiación Mundial del Comercio que el comercio internacional respete las normas fundamentales del trabajo de la Organización Internacional del Trabajo: prohibición del trabajo infantil, abolición del trabajo forzoso, derecho de sindicalización y negociación colectiva y no discriminación del empleo, entre otras. Proteger estos derechos no es poner trabas al progreso de los países pobres, como algunos pretenden, sino establecer unas bases mínimas para que se produzca un desarrollo sostenible". Junto con los derechos de la mujer, hay que establecer derechos de protección y evaluación en el uso de los recursos naturales, con información para el consumidor sobre el respeto a los derechos laborales y del medio ambiente. "Hay que facilitar el acceso de los países en desarrollo al mercado con un compromiso financiero mucho más generoso de los países industrializados, que incluya programas de ayuda comercial y la utilización de controles de capital para prevenir la inestabilidad financiera".

Respecto a la liberalización de los servicios, hay que defender el concepto del interés general. "Esto es importante en todo el mundo, pero especialmente en los países menos desarrollados, donde debería esiablecerse un marco regulador que evite las presiones de las multinacionales sobre los gobiernos de estos países para que privaticen sectores donde el Estado garanliza la universalidad de ciertas prestaciones. Cuestiones claves como la sanidad o la educación no se pueden dejar en manos del interés privado, que no responde a un compromiso con los ciudadanos, sino a la rentabilidad de sus inversiones".

Para que el comercio se someta a los intcreses sociales es necesario un desarrollo democrático de las estructuras de la Organización Mundial del Comercio. "Desde la perspectiva sindical nadie dis- cute que la apertura de los mercados puede y debe ser un factor de progreso general y contribuir a reequilibrar la creciente brecha entre el nivel de desarrollo de los distintos países. Por ello, el movimiento sindical dice sí al comercio mundial, pero un sí condicionado al cumplimiento de las normas laborales, a la defensa del interés público, al respeto al medio ambiente y a un trato justo hacia los países más débiles. Todo esto no puede lograrse desde unos compromisos difusos o desestructurales, sino que debe cimentarse en una normativa clara y en unos mecanismos de control eficientes y democráticos" (C. Méndez, "Por un comercio que respete y beneficie a los ciudadanos", El Pais, 3 de diciembre de 1999).

\subsection{Todos se fueron como habían llegado}

"Seattle fue el primer fracaso que no fue perjudicial para nadie". Estados Unidos, como anfitrión, llegó a defender sus propios intereses a toda costa; y sólo en un segundo momento prestó atención a los los otros temas. La Unión Europea solicitó ampliar la agenda con nuevos temas, previendo la presión mundial para que desmantelase su sistema de subvenciones a la agricultura. Los países en desarrollo llegaron con cautela, temiendo que sobre la mesa colocaran temas nuevos, los cuales podrían volverse en contra suya. Al fracasar las negociaciones, no se firmaron acuerdos que les dañaran todavía más. De aquí al 2003, una nueva ronda de negociaciones sobre el comercio internacional integrará algunos de los temas pendientes.

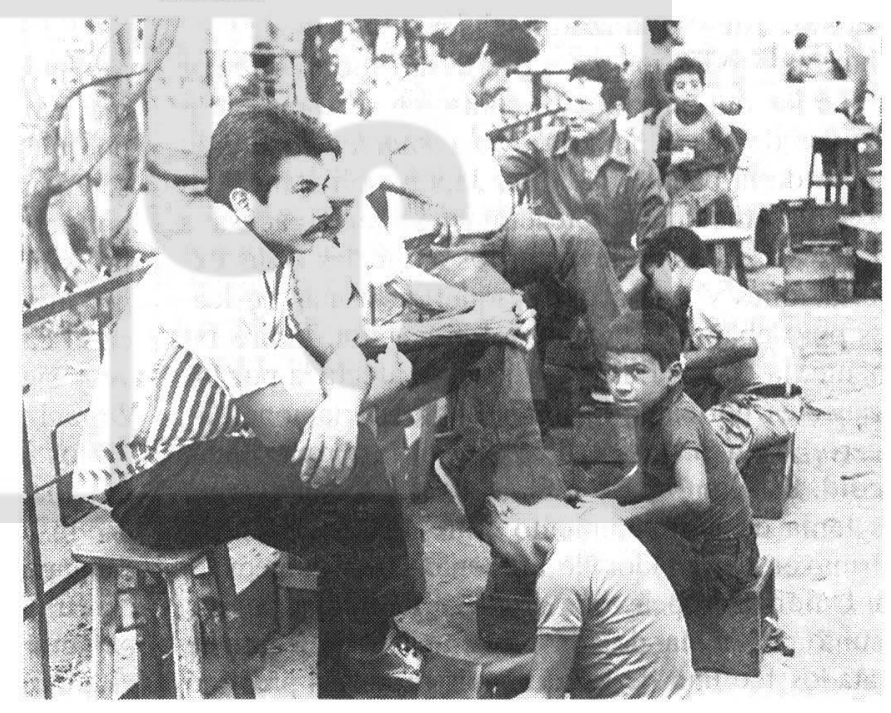


Estados Unidos deseaba desmantelar el sistema de ayudas a la agricultura de la Unión Europea y Japón, pero la misma intransigencia del primero generó la sensación de una derrota anticipada. Este punto de la agenda pasó a Ginebra y las discusiones se prolongarán hasta el 2003. Japón se negó a hablar de la reducción de aranceles a la pesca y los productos forestales ante la presión estadounidense. Varios países europeos defendían la "especificidad" de la pesca. Nada se perdió porque nada se avanzó. No hubo polémica mayor sobre los servicios, porque la mayoría (bancarios y telecomunicaciones) están en proceso de liberalización.

Los temas nuevos generaron mayor polémica: las inversiones, la competencia, la biotecnología y cl comercio de la electrónica. Estados Unidos y la Unión Europea, resguardando sus propios intereses, pretendieron abrir el tema del libre acceso de las inversiones extranjeras a otros países. Esto equivalía a reintroducir en la agenda el debate sobre el "Acuerdo Multilateral de la Inversión", que durante tres años se había discutido en los mismos países desarrollados y que había sido rechazado por la acción combinada de asociaciones sociales $y$ sindicales (Ch. De Brie, "Comment L'AMI fut mis en piéces", Le Monde Dimplomatique, diciembre de 1998; “L'AMI nouveau va arriver", mayo de 1999). La propuesta fue rechazada

Para el movimiento sindical, la mundialización debe basarse en la justicia social, la democracia y la igualdad. Estas consignas implican ciertas exigencias a países desarrollados y en vías de desarrollo. entre los manifestantes que acudieron a Seattle. En cuanto al comercio de la electrónica, prosperó la prórroga del arancel "cero" hasta el 2001. Para Estados Unidos el tema era crucial, puesto que domina las ventas y los servicios de Internet.

La agenda de los temas sociales comprendía la ayuda a los países pobres y la defensa de los derechos laborales. La iniciativa para ayudar a los países pobres provenía de la Unión Europea. Para ella era un tema antiguo. Sin embargo, en Seattle, los posibles heneficiarios no se sintieron halagados, porque podía ser un velo para desviar la atención del tema central, las ayudas a la agricultura europea y los aranceles a las exportaciones de los países en desarrollo. Aunque tanto Estados Unidos como la Unión Europea hablaron de ayuda, a través del sistema de preferencias a las importaciones o de reducción de aranceles, "al final, las promesas a los países pobres se quedaron huecas". Tal . como se indicó arriba, la propuesta de Clinton y la Unión Europea en cuanto a defender los derechos laborales fue recibida como una amenaza o una tomadura de pelo, por la razón ya señalada de que Estados Unidos no ha firmado ninguno de los tratados de protección de los derechos laborales impulsados por la Organización Internacional del Trabajo.

El medio ambiente, un tema solicitado por la Unión Europea, recibió un apoyo bastante amplio, al enlazarse con el comercio y el desarrollo sostenible. Al mismo tiempo que se recomendaban medidas para protegerlo, se advertía que éste no sería utilizado como una política proteccionista. Algunos países en desarrollo temían que se aplicaran sanciones comerciales por incumplimiento de estas medidas, al igual que en el caso de los derechos laborales. Un tema clave y siempre en litigio fue "la transparencia de la Organización Mundial del Comercio". La mayoría de los países en desarrollo protestó por su continua marginación en estas negociaciones, reiterando las quejas presentadas en la reunión de Singapur (1996). En Seattle, volvió a reinar la confusión sobre el avance de los temas y sobre las posturas de los bloques negociadores. Por ello, esta cumbre se clausuró sin que se suscribieran los 
enigmáticos borradores (F. Gualdoni, "Los escollos que la Organización Mundial del Comercio no fue capaz de salvar", El País, 6 de diciembre de 1999).

Terminada la reunión de Seattle, seguirán fluyendo nuevas reflexiones. Como señalara un mes antes el Congreso de la Internacional Socialista, se hace necesaria una profunda reforma de la estructura y la transparencia de la Organización Mundial del Comercio. Representantes de los países en desarrollo, junto con la diversa gama de manifestantes, han repetido que no es nada claro que "el progreso económico sea función del comercio exterior, cuando casi las cuatro quintas partes de su volumen se hacen de la mano de las empresas de los países desarrollados: el mundo no es una mercancía". Después de haber leído las proclamas de la "Declaración de París", no queda muy claro cómo se compaginan esos objetivos de la reforma del tan desigual orden económico mundial y de la inaceptable pobreza del tercer mundo, con la postura ortodoxa de Estados Unidos y la Unión Europea respecto a la liberalización del comercio exterior.

Entre estos dos bloques se han librado debates relacionados con la recíproca protección a la agricultura, pero siguen coincidiendo en la necesidad de liberalizar las inversiones de sus empresas en otras naciones. Esto equivaldría a resucitar el largo debate sobre el Acuerdo Multilateral de la Inversión. La Organización Mundial del Comercio no debe ser el eje del gobiemo mundial, sino uno de los apoyos. Como se ha reclamado en Seattle, "necesitamos la conjunción de la nueva comunidad política internacional, que tantos reclamamos, y de una efectiva sociedad civil a la que la emergencia del espacio público mundial comienza a otorgar presencia. Los movimientos ciudadanos han ido a Seattle a reclamarla y a decirnos que el patriotismo planetario de todos es necesario complemento del amor al país de cada uno" (J. VidalBeneyto, "La globalización del mundo", El País, 11 de diciembre de 1999).

\section{Unilateralismo o imperialismo de Estados Unidos}

La "batalla de Seattle" ha hecho rebrotar una abundante literatura, sobre todo europea, en torno al imperialismo económico, militar y político de Estados Unidos. Lester Thurow titulaba una de sus obras "La guerra del siglo XXI" (Head to head): la batalla económica que se avecina entre Japón, Europa y Estados Unidos. De 1992 a nuestros días, el viento de la guerra parece soplar a favor de Estados Unidos, aunque no podemos hablar de vencedores y vencidos. Es cierto que Japón se ha visto seriamente afectado por la crisis financiera, generada por su propio sistema bancario, quebrando un proceso de recesión latente desde el inicio de la década. También es cierto que los ritmos de crecimiento son menores en Europa, mientras que sus tasas de desempleo superan a las norteamericanas.

Aunque no se ha haya confirmado, economistas ecuánimes como P. Samuelson y J Sachs, han manifestado sus temores por la hinchazón de la "burbuja" norteamericana, la cual, al explotar, tendría serias consecuencias mundiales. No se trata aquí de especular sobre el futuro del euro, del yen y del dólar, sino del nuevo imperio político que amenaza dominar el siglo XXI, asentado en el imperio militar, económico e informático.

\subsection{Unilateralismo militar}

La política exterior de Estados Unidos estaría transitando desde un multilateralismo, donde el "líder" controla a las grandes instituciones internacionales, hacia un unilateralismo donde el legislativo republicano, sobre todo, y el mismo ejecutivo toman decisiones de acuerdo a sus intereses nacionales, traspasando la autoridad de aquellos organismos internacionales. Este fenómeno se observa claramente en el campo de la defensa militar. Pese a la finalización de la guerra fría y a la desaparición de la Unión Soviética, el ejecutivo de Estados Unidos sigue dedicando fondos multimillonarios a la defensa militar. De los 274 mil millones de dólares del año 2000 a los 331 miles de millones de dólares en el 2005. Clinton justificaba este incremento de los gastos por la aparición de nuevos "terroristas": "si nosotros trabajamos por la paz, nosotros tenemos también que hacer frente a las amenazas contra la nación, que en forma creciente apoyan los grupos terroristas y las naciones que se sitúan fuera de la ley" (19 de enero de 1999).

Estados Unidos está determinado a mantener su superioridad militar frente a todos los adversarios posibles o imaginarios. Ello ha generado un control creciente de la transferencia de tecnología civil, que - caso de la China - pueda ser utilizada para fines militares. Baste recordar que la Organización del Tratado del Atlántico Norte (OTAN) fue arrastrada, por la presión unilateral de Estados 
Unidos, a lanzar la "guerra humanitaria" de Serbia y Kosovo, transgrediendo la consulta al Consejo de Seguridad de Naciones Unidas (ECA, 1999, pp. 305-318). Esto le ha restado autoridad moral y legalidad para acusar a Rusia por su intervención "antiterrorista" en Chechenia.

Este militarismo estadounidense se refuerza en los discursos y en el presupuesto nacional de 1999. El Departamento de Defensa presentó su informe anual de ese año con estas palabras: "Por cuanto somos la única nación capaz de llevar a cabo a gran escala operaciones integradas (polivalentes) en regiones muy alejadas de sus fronteras, Estados Unidos ocupa una posición única... Para conservar esta superioridad, los Estados Unidos debe mantener siempre fuerzas preparadas para intervenir, polivalentes y capaces de llevar a cabo una amplia gama de operaciones y actividades militares". El Pentágono explica que para defender sus intereses nacionales, debe contar con esta capacidad para proyectar sus fuerzas armadas sobre regiones en conflicto y controlar toda resistencia. Esta capacidad permite a Estados Unidos dominar (estas crisis externas) y responder, aunque no cuente con una presencia permanente en la región, en donde sólo dispone de una infraestruclura limitada".

Todos estos discursos muestran cómo se ha acrecentado su conciencia y su ambición de poder, presto a defender sus intereses nacionales en cualquier región del mundo. Claramente lo afirmaba Clinton, en su discurso del 26 de febrero de 1999: "se podrá decir que no nos preocupamos por saber quién habita en este o aquel valle de Bosnia, quién es el propietario de una parcela de la selva en una esquina de África o de determinada zona de tierra árida en las riveras del Jordán. Lo que cuenta para nosotros no es el que estos países estén lejos o sean minúsculos, o que su nombre sea difícil de pronunciar. Lo que debemos preguntar y conocer son las consecuencias que para nuestra seguridad emanan de permitir que los conflictos se envenenen y se propaguen. No podemos y no debemos hacer todo y estar en todas partes. Pero, cuando están en juego nuestros valores y nuestros intereses, entonces podemos actuar y estar prestos a acluar" (M. T. Klare, "Washington veut pouvoir vaincre sur tous les fronts", Le Monde Diplomatique, mayo de 1999).

\subsection{Unilateralismo económico}

Esta prepotencia y este unilateralismo militar se reflejan y se repiten en la esfera económica. Richard N. Haas lo expone sin mayores ambages: "el objetivo de la política externa americana es trabajar, con otros socios que compartan las mismas ideas, por mejorar el funcionamiento del mercado y. promover el respeto a las reglas fundamentales. En la medida posible, con buenas maneras y, en caso contrario, por la fuerza. En última instancia, la regulación del comercio internacional es una doctrina imperial, por cuanto trata de promover un conjunto de normas a las que nos apegamos. Esto no debe confundirse con el imperialismo, que es una política externa de explotación". Otros autores no tienen empacho en utilizar el término imperialismo; tal es el caso del conservador Irving Kristol, para quien es algo normal "la emergencia de un imperio americano", indicando que "esto sucede porque el mundo quiere que suceda; una gran potencia puede verse conducida insensiblemente a asumir responsabilidades sin habérselo propuesto explícitamente".

Esto sucede también en las relaciones entre Estados Unidos y Europa. "Las naciones europeas son naciones dependientes, aunque gozan de una gran autonomía local". Incluso América Latina, antes refractaria a las intervenciones norteamericanas, "comienza a reconocer la legitimidad de Estados Unidos y [a aceptar] una americanización progresiva de su cultura popular y de su modo de vida... Nuestros misioneros viven en Hollywood...". Kristol cierra su comentario con una sombría advertencia: "esto es un imperio absoluto, con un mínimo de sustancia moral. Incluso si, de momento, el resto del mundo lo reclama y siente necesidad, hay que preguntarse si no llegará a hastiarse del mismo". En tal caso, habría que recurrir a otras formas de control. Haas R. opina que estas acciones unilaterales son peligrosas y por ello conviene integrar a otros socios, aunque sea en forma provisional. Así se llevó a cabo la guerra del Golfo y en el presente año, la represión contra Serbia. El interrogante es si cste género de política exterior se puede mantener en un mundo "donde la mitad de su población supervive por debajo de los límites de la pobreza y donde las cabezas nucleares se hallan diseminadas en más de una docena de países". A esta situación no vale responder: 
"Nosotros hemos ganado, los del otro campo no sólo han perdido, sino que han desaparecido".

\subsection{El reino informático cultural}

Aunque unos simples testimonios no representan una conciencia general, sin embargo, ayudan a entender recientes comportamientos de los poderes legislativo y del ejecutivo norteamericanos. Además, Estados Unidos agrega a su potencial militar y económico el poder de las industrias de la información. Hay una clara conciencia de la ventaja decisiva en el campo de la revolución informática. "El país de vanguardia en la era de la revolución informática será más poderoso que cualquier otro... En el futuro previsible este país es Estados Unidos... La supremacía nuclear era la condición necesaria para controlar las coaliciones del pasado. En la era de la información, esta supremacía es la que importa... La información es la nueva moneda del reino internacional y Estados Unidos está mejor situado que cualquier otro país para hacer valer su potencial de recursos materiales y logísticos por la vía de la información... Para Estados Unidos, el objetivo central de su política exterior en la era de la informática es ganar la batalla de los flujos de la información mundial, dominando las ondas, igual que Gran Bretaña dominó antaño sobre las olas de los mares".

Se ha iniciado no sólo la batalla intercontinental por el reino de la informática, sino también por "la privatización de las ondas". En Estados Unidos lue el gobierno quien impulsó la marcha hacia la electrónica, porque "la informatización completa de la economía era indispensable al crecimiento cconómico y a la hegemonía mundial". Ahora, "el sector privado dirigirá el desenvolvimiento de la 'infraestructura nacional de información'. Incumbe a las empresas privadas su creación y su funcionamiento". Así se explican las numerosas fusiones y concentraciones de empresas gigantes. Este proceso plantea un problema y un debate, puesto que se deja en manos de los intereses comerciales el control de la información, sin considerar el bien público, la responsabilidad social y las necesidades de la comunidad. En la mente de estas megaempresas estadounidenses, el reino futuro de la cultura informática debe confiarse a la creatividad e iniciativa privadas. En este escenario se están tomando las decisiones políticas en Estados Unidos, Japón y Europa. De ahí fluyen los derechos de propiedad privada de los servicios informáticos y la "tasa cero" al Internet. Se afianza así un nuevo reino cultural.

Nadie pone en duda los grandes aportes de las redes de comunicación en los campos de la comercialización económica, de la información financiera, de la investigación y de los nuevos sistemas de educación y aprendizaje a distancia, así como de la puesta al día de cuantos hechos, tristes o felices, se realizan en cualquier esquina del globo, que con razón llaman "aldea". Pero, al mismo tiempo, se levantan los temores por los valores y antivalores que estos monopolios comerciales y financieros van lentamente gestando en las conciencias, a modo de gota de agua que erosiona una roca. En el artículo, ya citado, sobre neoliberalismo y globalización se recoge una diversidad de testimonios autorizados que advierten sobre la pérdida de valores éticos, morales y tradicionales, al mismo tiempo que se inserta el nuevo modelo del homo oeconomicus, hecho para producir, para ganar y para consumir. Los países del tercer mundo estamos sometidos a este bombardeo cotidiano y subliminal, y no todas las conciencias son lo suficientemente sólidas para advertir este peligro. Este reino cultural tiene sus grandes aportes y también serios peligros.

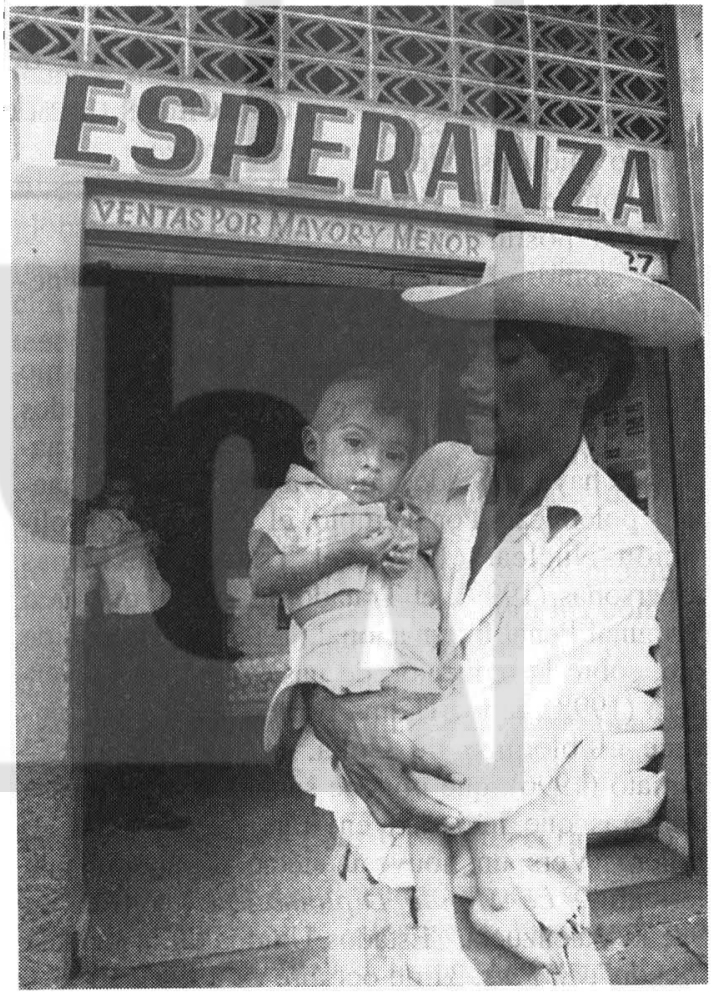


Si los poderes ejecutivo y el legislativo de Estados Unidos viven esta sensación de hegemonía en el campo militar, económico e informático cultural, se explica que no provoque mucha alarma el hecho de que pueda perder su escaño en Naciones Unidas, si no paga una parte de los 1800 millones de dólares que debe a la institución. Miembros del Consejo de Seguridad de Naciones Unidas no solicitaron su autorización para agredir a Serbia. La rama republicana del Congreso se opuso a la ratificación del Tratado de Prohibición Completa de Pruebas Nucleares (TPCPN), porque no se fían de las potencias nucleares antiguas y nuevas. $\mathrm{Al}$ mismo tiempo que han disminuido algunas ayudas externas, los republicanos impulsan aumentar el presupuesto militar, para poder intervenir, con manos libres y bien armadas, en cualquier esquina del mundo, donde surja una amenaza a sus intereses. Al candidato presidencial Bradley se le preguntó si apoyaría operaciones como la de Timor Oriental, y respondió: "hay 32 conflictos étnicos en el mundo y Estados Unidos no puede intervenir en todos. Sólo debemos implicarnos cuando estén en juego nuestros intereses nacionales". Al Gore tomó una postura intermedia: "somos el líder natural del mundo... y tenemos que pagar nuestras deudas a la ONU".

La sensación de superpotencia, el aislacionismo y otras razones ambiguas han motivado que Estados Unidos no subscriba algunos tratados internacionales y que haya aplicado unilateralmente leyes y sanciones polémicas. Por ejemplo, el Tratado de Proliferación Nuclear (1999), el Tratado de Minas Antipersonas (1999), el Tratado de Roma, que creó el Tribunal Penal Internacional (1998), el Tratado de Kioto, sobre la reducción de gases de efecto invernadero (1998), la ley Helms-Burton (1996), que endurece el bloqueo de Cuba, la ley KenndedyD'Amato (1996), que impone sanciones a empresas extranjeras que inviertan en Irán y Libia... (H. I. Schiller, "Vers un nouveau siécle d'imperialisme américain", Le Monde Diplomatique, agosto de 1998; J. Valenzuela, "Estados Unidos da la espalda al mundo", El País, 31 de octubre de 1999).

\section{Democracia versus mercado: "tercera vía versus capital internacional"}

Llegados a este punto parecería que no queda mucho espacio para un pos-neoliberalismo, en un mundo controlado por poderes hegemónicos. Este temor no tiene una sólida razón histórica. Entre las buenas lecciones que nos ha legado el siglo $\mathrm{XX}$ está el hecho de que la humanidad o la humanidad de hoy no tolera por mucho tiempo a las potencias hegemónicas. Tal vez la razón sea más sencilla: que los imperios se hunden por su propio peso. En el siglo XX fueron desapareciendo los imperios coloniales; surgió y sucumbió en forma cruenta el nacional socialismo nazi, aunque dejó esparcidos algunos cromosomas; se desintegró el gran imperio de los autocalificados socialismos reales. Es lógico esperar que el nuevo imperio, en su vertiente mercantilista neoliberal, siga agravando su crisis sistémica. Hay dos fuertes contrapesos que lo denuncian y lo sacuden: "el rechazo de los excluidos" y la oposición de grupos e instituciones de buena voluntad. Este será el fin del "fín de la historia".

Hemos señalado tres momentos de este rechazo: el foro económico de Davos, la reunión de Seattle y la Declaración de París. El profesor de Lovaina, Riccardo Petrella, agrega el listado de las cumbres mundiales donde se ha ido gestando la voz de los excluidos y de las agrupaciones democráticas. La cumbre del medio ambiente, en Río de Janeiro (1992), la cumbre de Viena sobre derechos humanos (1993), la cumbre de El Cairo sobre el problema demográfico (1993), la cumbre del desarrollo social de Copenhague (1995), la cumbre de Pekín sobre la mujer (1996), la reunión de Estambul sobre el crecimieto urbano (1997) y el rechazo del Acuerdo Multilateral sobre Inversiones (1998).

Dentro de la sociedad civil crece la conciencia de la democracia y del rechazo a los imperios. Los movimientos sociales y las organizaciones no gubernamentales han jugado un papel histórico en la consolidación de la concienca moral y de una demanda social, dice R. Petrella, como "expresiones 
vivientes y diversificadas de la riqueza creadora de las resistencias, de las luchas y de las innovaciones, que han marcado la vida de las poblaciones que sufren, que sueñan, que quieren vivir, que pretenden construir un mundo mejor para todos, más allá de las 'realpolitiks' cínicas de los poderosos". Se quiere un mundo diferente y es necesario ir definiendo las reglas y las instituciones de un gobierno político de la economía mundial. Ello requiere que esta toma de conciencia de los movimientos sociales ascienda a los parlamentarios, a los elegidos legítimamente por el pueblo, para que se vayan estableciendo las reglas y las instituciones de gobierno de la sociedad mundial. Crece el clamor mundial, avalado por la Declaración de París, de que el destino del mundo no puede quedar en manos de funcionarios y expertos de la Organización Mundial del Comercio, del Fondo Monetario Internacional y de los gobiernos de los países más desarrollados (R. Petrella, "El rechazo de los excluidos", El País, 19 de diciembre de 1999).

A estos clamores se suma la voz del Papa Juan Pablo II, cuyo mensaje del 1 de enero del 2000 solicita una mundialización en solidaridad, como fundamento para la paz: "Es necesario e improrrogable una renovación del derecho internacional y de las instituciones internacionales, que tenga su punto de partida en la supremacía de la humanidad $y$ de la persona humana sobre todas las otras cosas y sea éste el criterio fundamental de organización... En el inicio de un nuevo siglo, la pobreza de miles de millones de hombres y mujeres es la cuestión que, más que cualquier otra, interpela nuestra conciencia humana y cristiana. Es aún más dramática al ser conscientes de que los mayores problemas económicos de nuestro tiempo no dependen de la falta de recursos, sino del hecho de que a las actuales estructuras económicas, sociales y culturales les cuesta hacerse cargo de las exigencias de un auténtico desarrollo... La promoción de los pobres es una gran ocasión para el crecimiento moral, cultural e incluso económico de la humanidad entera... Puede que haya llegado el momento de una nueva y más profunda reflexión sobre el sentido de la economía y de sus fines..." ("Mensaje para la celebración de la jornada mundial de la paz", I de enero del 2000).

\subsection{El Grupo de los 20}

Joaquín Estefanía anuncia una epifanía: "ha nacido una estrella: el G-20". Un grupo intermedio entre el G-7 de los más ricos y el G-77, de los países en vías en desarrollo. Luego de la reunión de Seattle, en Berlín se reunió el Grupo de los veinte (G-20), con carácter sólo consultivo, para impulsar el diálogo entre los países más ricos y los principales países emergentes. Por supuesto, no aparecemos en esta lista de ricos o de emergentes: Estados Unidos, Alemania, Japón, Francia, Italia, Reino Unido, Rusia, Arabia Saudi, Argentina, Australia, Brasil, China, Corea del Sur, India, Indonesia, México, Turquía y Suráfrica. Se agregan representantes de la Unión Europea, del Fondo Monetario Internacional y del Banco Mundial. Estefanía recuerda que tanto el economista J. Sachs como la Internacional Socialista recomendaban algún organismo "que integrase a la mayor parte del mundo". El G-20 incorpora el 85 por ciento del PIB y las dos terceras partes de la población mundial. Aunque más democrático que el G-7, el G-20 sólo tiene un papel consultivo, "mientras que las decisiones se seguirán tomando donde siempre".

Los europeos temen un cierto espejismo, porque la sugerencia vino de Estados Unidos y Europa sólo cuenta con cuatro miembros del G-7. Después de las ambivalencias de la reunión de Washington, en octubre de 1998, esta reunión ha servido para recordar que es urgente una nueva arquitectura financiera internacional. Las crisis financieras, dice Estefanía, son, "en la era de la globalización, más frecuentes e imprevisibles que antes". El presidente del foro, Paul Martin, afirma que la globalización entraña riesgos "ya que reduce la capacidad de los estados de ofrecer proteción a sus ciudadanos". En la reunión de Berlín se han planteado interrogantes sobre cómo controlar los capitales en libre movimiento, los regímenes de tipo de cambio, el papel del Fondo Monetario Internacional, la responsabilidad de los inversionistas privados imprudentes... Pero este Grupo de los veinte no respondió a estas cuestiones. Aceptemos como un avance que se hayan planteado los problemas en forma de interrogante y que ahora los consultados sean veinte. El interrogante que nos queda es si los "emergentes" seguirán asistiendo como "invitados de piedra" (J. Estefanía, "Ha nacido una estrella: el G-20", El País, 19 de diciembre de 1999).

\subsection{De Florencia a Seattle: "la tercera vía"}

Poco antes de Seattle, en Florencia se reunieron algunos presidentes y jefes de gobierno, de tendencia demócrata: Blair, Clinton, D'Alema, Jospin, 
Prodi y Schröder. Una premisa y una pregunta. En opinión de Norman Birnbaum, de la Universidad de Georgetown, la premisa es que "la élite política global es incapaz de enfrentarse a una economía mundial, que ahora ha sido declarada oficialmente fuera de control”. La pregunta: “¿Es la tercera vía una alternativa?".

Desde la reunión tenida en El Escorial (Madrid), en julio de 1999, donde Anthony Giddens, de la London School, presentó los valores de la tercera vía, han aparecido una serie de comentarios que tratan de dilucidar la especificidad de este modelo y su relación con la globalización. Entre ellos están los comentarios del propio A. Giddens, Ralf Danhrendorf, Felipe González... Tanto o más importante que estas distintas lecturas es el hecho de que, por presiones de grupos y fuerzas sociales, los programas económico sociales de la posible tercera vía están evolucionando. Esto se ha observado en la reunión de la Internacional Socialista, donde se trató de conciliar el común denominador de los distintos gobiernos.

Nos centramos, de momento, en la reunión de Florencia, donde estos jefes de gobierno se vieron acorralados por los flujos y reflujos de las presiones nacionales. Birnbaum deduce que estos jefes de gobierno "se hicieron eco de la más vulgar de la creencias: que como el mundo es como es, no puede ser de otro modo.... Clinton dio a entender que la economía global requería controles sistemáticos". Sin embargo, las fuerzas conservadoras de Washington han empujado al ya citado economista Joseph Stiglitz fuera del Banco Mundial, "por describir el 'consonso' sobre la liberalización y el libre comercio como un fraude intelectual".

Cada jefe de gobierno enfrenta sus propias turbulencias. Tony Blair sabe que el capitalismo internacional puede zarandear la libra, símbolo de la soberanía nacional. Clinton tiene que moverse entre las presiones de las grandes empresas y el apoyo electoral que le viene de las clases trabajadoras, los negros y los sindicatos. Gerhardt Schröder se ha visto sometido a mayores presiones: el retiro de su ministro de hacienda, Oscar Lafontaine, en protesta por la marcha atrás inicial; si sostiene que el Estado tiene deberes para con sus ciudadanos, el gran capital puede retirarse de Alemania. Últimamente, Schröder se ha acercado a Jospin y ha abandonado el informe Blair-Schröder. Por su parte, Jospin tiene que moverse entre la ampliación del Estado de bienestar, junto con la modernización de la economía, frente a la invasión teórica y real del capital internacional. No resulta fácil vincular los ideales de la tercera vía en el océano de la globalización.

Afortunadamente, a continuación vino la batalla y la sacudida de Seattle, cuya resonancia sorprendió a Estados Unidos. Esta resistencia del integrado grupo de manifestantes se venía preparando desde hacía muchos años y los medios de comunicación estadounidenses quedaron sorprendidos por este organizado movimiento. El problema se replanteará en las próximas elecciones presidenciales. "Sus donantes financieros insisten en el libre mercado, pero un gran número de demócratas y ciudadanos independientes exigen que se controle la economía global". Birnbaum cierra su comentario con una sugestiva conclusión: "los socialistas europeos no tienen por qué abandonar sus principios para unirse a los demócratas estadounidenses, cuando gran parte de nuestro Partido Demócrata está recuperando su propio pasado socialdemócrata. El grupo que se reunió en Florencia volverá a encontrarse en Düsseldorf en marzo. Por entonces puede que hasta Schröder invoque al hijo olvidado de Renania, el doctor Karl Marx. De hecho, es posible que Clinton no le ande a la zaga; podemos suponer que nos enteraremos de que, a fin de cuentas, nuestra revolución estadounidense fue el principio de la democracia radical. Eso es verdad, y después de Seattle, muchos estadounidenses están empezando a preguntarse si no necesitamos otro New Deal" (A. Guiddens, "Los reveses de Schröeder y la tercera vía", El País, 26 de julio de 1999; N. Birnbaum, "De Florencia a Seattle", El País, 20 de diciembre de 1999).

\section{La "Declaración de París": el agujero negro}

En 1987, M. Gorbachov se preguntaba, en el capítulo tercero de Perestroika: “¿Cómo vemos el mundo actual?". Lo descrito en esos seis últimos capítulos sigue teniendo plena actualidad, porque Gorbachov se opuso a los imperios y al enfrentamiento de los imperios, a su "manía armamentística"; propició el diálogo por la paz y habló de los países en desarrollo, "que tienen problemas cien veces mayores que los nuestros". Opino que Gorbachor avala la "Declaración de París", ante el "agujero negro" que ella describe. En la introducción recogemos los temas más importantes de esta declaración, pero no hay espacio para extenderse en todos ellos. Hemos extractado abundantes testi- 
monios que recomiendan profundas reformas de las instituciones internacionales (Fondo Monetario Internacional, Banco Mundial, Organización Mundial del Comercio, Naciones Unidas...), "para adaptarlas a las nuevas realidades y dotarlas de nuevos instrumentos de previsión y acción. Asegurar una mayor transparencia del sistema financiero internacional a través de reglas...". Abundan la literatura y las políticas para "dar respuestas rápidas y sostenidas en el tiempo al problema de la protección del ecosistema".

Los derechos humanos. Persisten otros temas que, sin posibilidad de desarrollarlos en su debida extensión, son parte integrante de este agujero negro: "lucha por los derechos humanos y la democracia". A este respecto, vale la pena releer las veintidós breves páginas del mensaje de Juan Pablo II, sobre los derechos humanos, fundamento de la paz, del 1 de enero de 1999. El siglo XX ha sido testigo de los mayores "crímenes contra la humanidad", cometidos por los sucesivos imperios; y a los crímenes cruentos se suma ahora la insolidaridad de determinadas instituciones internacionales y del modelo que propugnan que, sin campos de concentración y armas letales, generan la exclusión de millones de seres humanos del bienestar mundial. No puede calificarse de orden mundial una estructura de poderes que margina a dos tercios de la humanidad. Esto se dijo cn Scattle y vuelve a aparecer en la "Declaración de París".

Las fuerzas centrifugas. Hemos recordado que el siglo XX no tolera por mucho tiempo a los imperios opresores de la autodeterminación y la democracia. La historia enseña que los imperios generan sus propias fuerzas centrífugas o, como lo ha dicho A. Schelesinger: "la integración y la desintegración se alimentan mutuamente. La globalización ocupa el puesto de mando y dirige a la humanidad, pero - al mismo tiempo- impulsa a las personas a buscar refugio a sus poderosas fuerzas, que están más allá de su control y comprensión. Se retiran a unidades familiares, inteligibles, prolectoras. Ansían la política de la identidad. Cuanto más rápidamente se integra el mundo, más personas se refugiarán en sus enclaves religiosos, étnicos o tribales" (ECA, 1998, p. 900). Paradoja de un mundo que llamamos "aldea" globalizada y

nue nunca ha estado tan fraccionado por los nacionalismos, la xenofobia y los conflictos étnico religiosos. Un mundo donde crece el número de los emigrantes sin patria y de los marginados en su misma patria. La miopía de la globalización es no percibir este proceso de desglobalización.

La pobreza y la deuda externa. El documento Bases para un plan de nación dijo que en nuestro micro-reino de El Salvador el "nudo-gordiano" es la pobreza estructural y la exclusión social. La "Declaración de París" afirma que esto es cierto a nivel mundial, y lo ubica como el primer manchón del agujero negro: "Lucha contra la pobreza y el hambre, contra la explotación y la desigualdad de acceso a los recursos económicos y tecnológicos mundiales. Anulación de la deuda de los países más pobres...". La literatura sobre la deuda externa desborda estas páginas. A la reunión del G-7, del Fondo Monetario Internacional y del Banco Mundial, lenida en Colonia, en junio de 1999, llegaron unos 17 millones de firmas exigiendo la anulación de la deuda externa de los países más pobres. El número de organizaciones no gubernamentales que analizan el problema y renuevan propuestas de reformulación y alivio, se ha multiplicado. Desde 1994, Juan Pablo II se había sumado a estas voces, en su carta "Cercano el tercer milenio". Muy cerca de nosotros se ha firmado la Declaración de Tegucigalpa: "Sí a la vida, no a la deuda", el 27 de enero de 1999. Algo muy turbio e inmoral corre en este proceso, cuando "desde el estallido de la deuda externa en 1982, los países del tercer mundo han reembolsado cuatro lo que debían, para acabar encontrándose hoy 3.5 veces más en- 
deudados que entonces". El pecado no está sólo del lado de los acreedores; también hay gobiernos deudores cómplices del mismo pecado.

Al terminar el año, "una voz clama en el desierto": Francia y el Reino Unido anunciaron sus planes para condonar la deuda externa a distintos países pobres, tal como se habían comprometido en la reunión de Colonia. Francia programó anular unos 7000 millones de euros en los años 2000 y 2001. El Ministro de Economía británico, Gordon Brown, habló de una condonación de la deuda por "centenares de millones de dólares" a 25 países del tercer mundo. "Tenemos que hacer que se mueva el proceso de reducción de la deuda de los países pobres". Parece que Estados Unidos lanzará una propuesta similar. En la reunión de Colonia se dijo que la condonación programada de 70000 millones de dólares sólo representaba el 3 por ciento de la deuda total. Algunos comentaristas y organizaciones no gubernamentales afirman que esta iniciativa será de poco alivio para los países más endeudados, quienes seguirán pagando unos intereses por servicio de la deuda, que representan cuatro veces lo que gastan en salud y educación.

Ahora queremos ver el lado positivo de "esta voz que clama en el desierto". El lado positivo es que los gobiernos británico y francés quieren asegurarse de que los fondos que ahorren los países pobres se dediquen a fines productivos. Existe "una garantía de que si la deuda se cancela, el dinero irá a parar a programas de educación y sanidad o lucha contra la pobreza, y esa es la condición en que se proporcionará la condonación futura de la deuda. No se trata de aliviar la deuda por aliviarla; se trata de la reducción de la pobreza como resultado de la condonación de la deuda, y también -y ese debe ser nuestro objetivo- de conseguir el desarrollo económico para que estos países puedan crear empleo para su población". La "Declaración de París" agrega una apostilla: "el año 2000 debe ser decisivo para que la anulación de la deuda dé paso al relanzamiento de las inversiones en los países concernidos" (Agencias, "Francia y Reino Unido perdonarán la deuda de los países más pobres", El País, 19 de diciembre de 1999; F. Gualdoni, "La etenera deuda de los pobres", El País, 25 de julio de 1999).

Estas buenas iniciativas, sin embargo, siguen despertando ciertas dudas y escepticimos. Sabemos que la génesis y el proceso de cancelación de la deuda están plagados de atropellos financieros de parte de los acreedores, y de derroche y corrupción, en bastantes gobiernos deudores. Sabemos que el principio regulador fue "si deben, deben pagar", aunque se había pagado con creces. Sabemos que el Fondo Monelario Internacional, en coalición con la gran banca comercial, utilizó el gravamen de la deuda externa para imponer a los deudores la receta universal de los programas de estabilización y ajuste estructural. Estos programas eran necesarios por otros motivos y con otros modos. Sabemos que la losa de la deuda externa ha gravado más duramente a los pobres de los países deudores, por dos razones: en estos países, la estructura fiscal es regresiva y pagan relativamente más los que relativamente tienen menos. Ahora se descubre que el servicio de la deuda externa paralizó las inversiones en educación, salud e infraestructura social, fuentes requeridas para el desarrollo de estos pueblos. Los pobres fueron desheredados del presupuesto nacional. Para esas instituciones financieras internacionales lo importante era la "estabilidad macroeconómica", y todavía seguimos oyendo el mismo "canto de las sirenas". En este sentido, el discurso del presidente del Banco Mundial, James Wolfensohn, "La otra crisis" (octubre de 1998) también es "una voz que suena en el desierto" (ECA, 1998, pp. 1003-1009)

¿Y la otra deuda? Queda siempre una pregunta: estas iniciativas de alivio y condonación de la deuda, en sí laudables, ¿son prueba de una auténtica juslicia solidaria de los países ricos hacia los países pobres? La razón es obvia: estas iniciativas contrastan con esa prepotencia de los gobiernos poderosos en el control del comercio internacional, en el proteccionismo claro o encubierto de su producción y exportación, en las barreras arancelarias y no arancelarias, en los repetidos intentos por imponer el Acuerdo Multilateral sobre Inver- 
siones, en el terco principio del "mercado regulador", en la marginación y oscura transparencia con la cual se han modulado los borradores y los acuerdos comerciales. Por ello, la negativa de Seattle ha sido interpretada como una victoria de los países en desarrollo. En las relaciones asimétricas del comercio internacional se ha ido generando la "deuda primaria original", de donde dimana, como consecuencia, la impagable deuda externa. Son dos deudas que se retroalimentan. Se impone la reestructuración de esas instituciones y organismos internacionales como una tarea del nuevo milenio. No se trata de destruirlas, sino de reconvertirlas, en forma concertada y civilizada.

\section{A modo de postdata: el documento final de París}

Lionel Jospin invitó a la Internacional Socialista a "estudiar el capitalismo para reformarlo". El documento final, que sería avalado por los 170 partidos participantes, hace una síntesis entre las contribuciones francesa, británica, alemana (el Maniliesto de Blair y Schröder), española, italiana..., subrayando, como rasgo común, su oposición al "fundamentalismo conservador". T. Blair invitó a los socialistas a no convertirse en "guardianes rígidos de dogmas trasnochados frente a la nueva realidad de la mundialización". Manteniendo la debida flexibilidad, debe quedar claro que "no hay mercado de trabajo sin los derechos fundamentales para los asalariados". Si la izquierda progresista mantiene su fe en el mercado, esta fe debe también lijar "un cuadro reglamentario bien concebido que logre el financiamiento de servicios públicos de primera calidad". Jospin habla de un "socialismo democrático". Conviene recordar que en Europa occidental se vivió, durante décadas, la coexistencia de los "hermanos irreconciliables socialistas" (H. Cole): el socialismo centralista de partido único y planificación central, y el socialismo democrático pluripartidista, con sus progenitores E. Berstein, K. Kaustky, L. Blum... Desde esta perspectiva, L. Jospin defiende la modernidad de la social democracia. "Por lo que concierne a la crea- ción de riquezas y distribución de los recursos, la superioridad del mercado sobre la planificación es incontestable. Sin embargo, nosotros no hacemos del mercado un valor. El mercado es un instrumento, eficaz y precioso. Pero no es más que un instrumento. Debe ser regulado. Debe quedar al servicio de la sociedad".

L. Jospin agrega que "el socialismo es un dehate. Ahí veo la vitalidad de nuestra reflexión, el signo de la fraternidad que nos anima. Cada uno de nuestros movimientos busca la modernidad. Cada uno lo hace a su manera. Con sus referencias, con su historia, con su cultura política. Y esto está muy bien. La fuerza de la internacional socialista es saber conjugar la unidad con la diversidad. La diversidad, pero sin diluir nuestra identidad común. Todos nosotros somos socialistas democráticos. La unidad, pero sin afincarnos en un dogmatismo, nutriéndonos de nuestras experiencias los unos y los otros, vivimos en armonía con nuestro tiempo". Jospin enfatizó el objetivo del pleno empleo, remachando que "no tiene sentido un socialismo $\sin$ igualdad", aunque se trata de una igualdad donde hay sus diferencias. Queda la tarea de ir cambiando la sociedad.

En resumen, se trata de un socialismo plural y pluralista, que rechaza igualmente "la tendencia al Estado mínimo" como la "sacralización del mercado". Los poderes públicos deben favorecer una economía de mercado eficaz, pero deben sobre todo garantizar la igualdad de oportunidades entre ciudadanos y ciudadanas, asegurar sus derechos universales. La declaración termina señalando las "insuficiencias" de la Organización Mundial del Comercio y de las instituciones financieras internacionales. Se reclama que en el año $2000 \ldots$ se puede iniciar la anulación de la deuda de los países más pobres.

¿Hacia un pos-neoliberalismo? Tenemos los planos y nos queda la tarea de ir levantando los edificios (M. Noblecourt, "Lionel Jospin invite l'Internationale Socialista á 'penser le capitalisme pour le réformer", Le Monde, 8 de noviembre de 1999). 